\title{
Clarifying the Creative Consumer: An Abstract
}

\author{
Karen Robson and Matthew Wilson
}

\begin{abstract}
The future of marketing involves consumers taking a more active role in the marketing process. Reflective of this is the fact that over the past decade, many researchers have described, investigated, or discussed the creative individuals who engage in innovative activities with existing market offerings. Because the literature is fragmented and the terms used to describe and explain the actions and implications of these creative individuals are highly varied, there is no common understanding of the creative consumer construct and how it fits in with existing literature on consumer innovation. As this trend in marketing appears to be growing stronger and will only become increasingly important for marketing practitioners and researchers in the future, there is a need to synthesize existing research. In other words, who are creative consumers? What are the important conceptual and practical differences between the various terms used in literature to describe consumers who engage in innovative activities? What is their output? In order to answer these questions, a common language to discuss this phenomenon is required. Providing clarity and a common language around the creative consumer is the goal of this paper.
\end{abstract}

References Available Upon Request

K. Robson $(\bowtie) \bullet$ M. Wilson

Central Michigan University, Mount Pleasant, MI, USA

e-mail: robso1k@cmich.edu; wilso6m@cmich.edu 